\title{
Performance-based Conflict Resolution Training for Children
}

Fiona McAuslan

\begin{abstract}
This article explores the development of The SALT Programme: Creative Solutions to Conflict, which is a National School programme linked to the SPHE curriculum. The first pilot project was undertaken in 2005 in Donabate Portrane Educate Together. The research from this pilot programme formed the basis for my Master's Thesis, which looked at whether this type of education was effective in changing the views and behaviours of children in resolving conflict. The outcomes were seen as positive and so the programme was published. Since then, the programme has been implemented widely in schools with teachers showing considerable interest in being trained in the SALT Process. This has precipitated the development of a full teacher training programme for teachers, delivered through Drumcondra Education Centre and further adult education training, including a HETAC Level 7 mediation training.
\end{abstract}

\section{Keywords}

Conflict resolution, resolution training for children, conflict, creative solutions for conflict

\section{Introduction}

Conflict is part of life. We spend considerable time dealing with it; in our families, our places of work and in our relationships. Its effects can be devastating, yet, for all its prevalence and chaos we rarely have any training in how to handle it. We rely on an assortment of cultural and familial influences to teach us what to do. It is, however, possible for us to learn new ways of handling conflict. By understanding what conflict is and how it escalates, we can choose different ways of resolving conflict, and by learning new skills, we can improve our ability to turn disputes and rows into possibilities for resolution and growth.

Over the last decade, Drumcondra Education Centre, one of Ireland's state-run centres providing continued professional development for teachers, has been developing conflict resolution education for teachers and parents. This work has been based on the SALT Process, a set of conflict resolution techniques for addressing everyday disputes. The educational programme is called The SALT 
Programme: Creative Solutions to Conflict.

Conflict resolution processes are designed to be useful. They help us to reach mutual understandings, which in turn help us negotiate new ways forward. They link social and emotional skills with negotiation techniques and build paths to agreement. The paths in themselves can deliver real, incremental change in how we handle our conflicts and present a natural framework for socio-emotional learning. There is a natural link between conflict resolution and Social, Personal and Health Education Programme (known as the SPHE Programme), and this programme which puts considerable importance on self-awareness, communication as well as collaborative problem solving. When one looks at the aims of the SPHE Curriculum for National Schools, one sees a natural fit for conflict resolution education.

Conflict resolution processes also have the capacity to reduce time and effort needed to deal with conflicts in the classroom. The sort of rows and disturbances that take away from instructional time can be resolved by the students themselves with new skills, helping them to focus on school instead of being distracted by unresolved issues between them. For example: two little boys who had been fighting so much that they were not allowed in the playground at the same time, learnt how to express their anger differently (STOP: how can I calm down?). They used the skill of "I feel..." to talk about how they worried about having no friends (ASK: What do you feel?). They realised, as they thought about their problem, that they were fighting over their friends (LISTEN: What do I understand of what you feel). They used the conflict triangle to understand the underlying needs and interests they both had and worked through the stages of the SALT Process to problem solve together (TALK: What can we do to solve the problem together?). They finally were able to walk into the yard together. Their answer was "If we are friends, we will not be alone. We know how that feels".

One of the programme's key features is its basis in performance methodology used by classical musicians. This methodology focuses on increasing the capacity of students to access their best skills creatively in the moment as they need them. It is one thing playing in your front room when nobody but the cat is listening. It is quite another doing so in a full hall. The physiology a musician experiences in performance, with its triggers of anxiety and possible stage fright, is exactly the same as the physiological reaction triggered in us when we are in an escalating row or conflict. Musicians counteract this stage fright by a particular type of structured practice, which increases their ability to perform in the moment and thereby preventing stage fright. This method is applicable to conflict, as we can also create structured practice routines that can improved our ability to stay calm in "hot" situations.

This for me was a natural link to make, as for twenty five years of my working life I was a symphonic violinist and for fourteen of those years I was also a union negotiator. I spent almost as much time negotiating workplace conflict as I did playing in the orchestra for whose members I was negotiating. Alongside me were my orchestral colleagues, which gave me an unusual opportunity to compare how the same group of individuals coped with the performance stress of the concert platform with the stress of negotiating high conflict disputes. The feelings of stress and anxiety felt the same in both environments, but how we handled them was quite different. At the negotiation table, depending on how nervous we felt, we would struggle. However, when it came to the concert platform our competency 
level for performing was above that of rehearsals, despite, or because of, the adrenalin flowing through our veins. I asked myself the question: what was different about each setting? The answer was simple; we were trained to deal with the realities of one but not the realities of the other. We had extensive experience as musicians, underpinned by the development of knowledge and skills, and on the other hand we had limited or no experience in negotiating the resolution of conflicts, and negligible knowledge and skills.

Like musical performance, each conflict situation is unique and this requires us to access and use our skills in a new and different way. But, unlike conflict experiences, the musician tends to have a musical score. And, there is an opportunity to rehearse prior to the performance. When dealing with conflict, we not only need to remember what we have learned, but also to select the relevant response, which we feel is appropriate for the circumstances (Bodine and Crawford, 1998). It is therefore not enough to teach a set of skills with a process and expect individuals to be proficient. We have to develop the capacity to deal with each conflict as it arises, effectively selecting and executing the right skills for that situation. The performance methodology of the musician focuses on increasing that capacity to produce skills in a unique situation under pressure and utilises brain plasticity, the ability for the brain to change and grow to maximum effect (Schwartz \& Begley, 2002). Quite simply, musicians' practice grows the brain to be good at what is being practised. It is not merely knowledge of, but a capacity to "do"; to put that knowledge and experience into action.

As we know when we are in conflict we feel anxious, we fight for the right words, trying to keep our emotions under control. When we are under pressure like this, our amygdala kicks in and floods our brain with adrenalin, shutting off the language centres of the brain (Goleman, 2007). Just at the time we need to think the clearest and with most effect, our brain effectively switches off. Musicians treat this surge of adrenalin as a normal part of their working life and use practise routines to prepare for this phenomenon. These practice methods are highly structured and have been the musicians' way of life for hundreds of years. We have found that the methods used can easily be adapted to conflict resolution education for children. Helping them to find the capacity to act effectively when they too are under pressure.

Musical instrument lessons are largely conducted through music, with around $90 \%$ of the lesson time given to playing the instrument. This maximises the students' experience of playing and helps them, not only to gain in confidence, but to understand what it is to be a musician. The medium we use to resolve conflict is language, therefore conflict resolution programmes for children should maximise language throughout. Using discussion circles and stories, interactive games and drama help children to express themselves and connect with each other through language. The more proficient they become with conversation, the more adept they will be in the very medium they use to resolve conflict. So, similar to the young player, they learn to be peacemakers by talking, listening and negotiating in the lessons. This resource places strong emphasis on learning through language. If staff and children can express themselves well in conversation and connect with each other through language, they will naturally improve their conflict resolution skills. The sort of activities included are all taught through circle time, 
with the teacher encouraged to open up discussion with the class. There are stories and lists of questions that resource the teacher to do this. The games and exercises are each around 10 minute in length and represent a building block skill, such as managing anger, or asking an open question. These exercises can be used by the teacher on their own to practice specific areas of the programme with one or more children, for example counting to 10 and calming down when you get angry can be utilised almost daily with particularchildren!

Musicians put a huge value on structured practice. In one of his books, Daniel Goleman (2003) describes the findings of a series of fmri scans done on a number of elite concert violinists' brains. These scans showed a significant growth of grey matter in the areas of the brains required to play the violin. These artists had all done around 10,000 hours of practice before reaching adulthood and seemed to have developed their brains to be fit for the task, leaving their minds free to engage with the creative uniqueness of each performance. We all marvel when we hear a great musician play. What we should remember is that the great, creative interpretation we are listening to sits in and around a strong structure of skills and they have music theory that binds those skills into a form.

The artistry involved in resolving conflict also sits within an integrated set of skills. We can only transfer the great art of peacemaking to the next generation if we understand how to transfer and integrate that skills set. Musicians understand that there are no short cuts to skills integration, and, quite simply, the more children rehearse, the more they improve their capacity to act effectively in a real situation.

Within The SALT Programme: Creative Solutions to Conflict, there is a portfolio of children's interactive exercises, which range from listening games, to anger ladders to mimes, and poetry. There are several different exercises on each skill, which break them down into small component parts. For example, a game, where each child mimes another child's body language, acts as a precursor to a reflective listening exercise. This is a critical part of skills training. Each piece of the puzzle is practised and put together, allowing the student to learn good habits in easily digested steps.

Finally, just as the musician needs to have the intention of bringing music to life for other people so our children need to develop the intention of peacemaking. The S.A.L.T. approach within the programme is a conflict resolution process which helps with this. It presents the elements of conflict resolution in easily remembered steps, which can be used at in response to whatever situation is occurring. For example, for one person 'STOP' will involve learning to use anger management techniques; for another 'LISTEN' will be about learning not to interrupt. The objective is to move from experiencing conflict as one person against another towards understanding it as a problem to be mutually solved. They experience this shift for themselves in their own disputes, through developing their own better communication is the life blood of learning. 


\section{The S.A.L.T. Programme: Creative Solutions to Conflict}

This resource contains a conflict resolution process for schools, used in the classrooms, in playgrounds, and in staff and board rooms, and is based on the everyday skills and concepts from the world of Alternative Conflict Resolution. There are four main sections of the programme:

1. Myself in Conflict - Self Esteem and Awareness, Anger Management.

2. Myself and Others - Collaboration and Negotiation in Conflict.

3. Relating to Others - Communication in Conflict.

4. Myself and the World - Conflict Resolution:S.A.L.T.

Each of these mirror the four main educational pillars of the SPHE Curriculum: Myself, Myself and Others, Relating to Others, Myself and the World. With one step, these four pillar can also create a complete set of conflict resolution skills for children and adults.

\section{Self-Esteem}

Individuals need a sense of their own goodness and power when they face difficult situations. Self-esteem can help people think clearly and gain confidence. It enables us to make better decisions and then act on them. If low self-esteem can make us defensive and fearful. Positive self-esteem helps us see the good inothers.

Self-Esteem as a Skill in Conflict: When faced with conflict, good self-esteem enables us to think clearly and more objectively about the situation we are experiencing. This in turn helps us to access conflict-resolving skills.

\section{Collaboration}

Collaboration can bring all strengths together in a creative and positive way. If we learn what we are good at as team players, it will help us gain confidence in co- operating when faced with more serious issues. Affirming and being affirmed in our strengths gives us a stronger foundation for tackling conflict more effectively. The more we recognise teamwork in our daily lives the more success we will have with conflict.

\section{Collaboration as a skill in Conflict}

Collaboration is at the heart of good conflict resolution. If conflict is resolved in a way that includes everyone as part of the answer, then the solution will be better for all. Seeing conflict as a cooperative problem to be resolved can create more choices. 


\section{Communication}

The heartbeat of good communication is the genuine intention to understand. Listening carefully, with real attention, can connect people. Good communication needs to be interactive. The speaker has to articulate clearly and the listener has to help the speaker say what he/she wants to say so that they can understand them. Speakers have to help others listen so they feel heard. Sharing information and experiences with each other helps break down the sense of isolation that can create difficulty when dealing with people.

\section{Communication as a skill in Conflict}

Through communication, people in conflict start to open their minds to other possibilities and this, in turn, develops into understanding and empathy. These are essential for any resolution.

\section{Conflict Resolution}

Conflict is part of everyday life. The experience of conflict can diminish our ability to think and act effectively. However, through better self-awareness, collaboration and communication we can turn conflict into an opportunity for positive resolution. Through enhancing the socio-emotional skills we already use in our daily lives we can learn to deal with conflict in a more positive way.

\section{Conflict resolution a skill in Conflict}

This easy-to-remember four step process gives is a framework to resolve all types of rows and disputes. Each step is linked to the skills taught in the SALT Programme, bringing them together in a ready to use conflict resolution process

\section{Stop, Ask, Listen, Talk - The S.A.L.T. Process}

Children love sprinkling SALT on their disputes. It encourages them to add something to their arguments to change the flavour. They find it an easy way to try the skills they have learnt. Teachers report children running up to them in the Yard saying "We've sprinkled SALT and we can nearly sort things out......" or as one child in the Midlands said "We SALT things out in our class".

Within the pack there is:

- A Teachers' Manual, which outlines the dynamics of conflict, how it escalates and what skills are needed to resolve it. This manual can be used as a handbook for the teachers themselves to learn how to resolve their own conflicts, as well as give them the key teaching elements of the programme for children.

- A Resource Book, which contains six original conflict stories based on real life children's rows. In this resource there are also all the games and exercises needed to make up the lesson plans for the class. Any additional materials, such as crayons and paper needed can be found in mostclassrooms.

- 9 posters for the classroom. 
- Conflict Assessment Forms, which the teacher can fill in with the student and can both help the student talk about what has happened and help record any rows that happen in the class.

\section{Teacher Training Programme}

From the first time SALT appeared in front of teachers as a children's programme, the teachers themselves have asked for training in the skills. The teacher training programme has aimed at enhancing teachers' negotiation and conflict resolution skills for the classroom and daily work lives. It has been about the teachers and how they work; not only about their subject matter knowledge. If we are to take seriously the need for conflict resolution education, then we have to take seriously the need for teachers themselves to build a better capacity to deal with it themselves. Like all aspects of the SPHE syllabus, this area of education is more about being and doing, rather than knowing and imparting that knowledge. This training is laid out as follows:

Myself and Conflict: STOP, focusing on the dynamics of conflict and how it affects us. It looks at personal conflict styles, how our values are triggered and the way we form our assumptions. Participants get to know themselves better in relation to their response to handling challenging interpersonal issues, as well as gain confidence both at a personal and professional level in handling conflict with colleagues, parents, students. The types of conflicts are drawn from the experiences of the participants themselves and range from inter-personal, staff room, teacher/teacher, teacher/parent, teacher/Principal, teacher/pupil and classroom disputes

Relating to Others: ASK, looks at a number of collaborative resolution process models that can be used to deal with the cases discussed in the first session. It focuses on process steps and links the practical experience to the theory of conflict resolution, outlining the skills used within the models. Participants learn listening skills, how to reframe language and ask open and clarifying questions. This module also focuses on how to identify the underlying issues and differentiate bullying as a particular expression of conflict requiring a unique set of techniques.

Communication Skills: LISTEN, Participants learn listening skills, how to reframe language and ask open and clarifying questions. This module focuses on how to identify the underlying issues and differentiate between bullying and conflict. This session demonstrates the various dynamics that are present in negotiation and show how to use these dynamics to create good outcomes for children and staff, enhancing the participants' negotiation skills base.

Myself and the World: SALT Process: This session focuses on how to identify the issues in a row or dispute, understand and summarise the underlying issues. Participants will learn how to then use the Salt Process to option develop suitable outcomes and reach agreement.

SALT Programme: Creative Solutions to Conflict: This final session focuses on how the SALT Programme for children is taught in the classroom. Participants reflect on their learning from earlier sessions share with colleagues how this will inform their classroom teaching and how to implement it in the classroom with a view to enhancing students' skills. 
The above training has proved popular because of its emphasis on supporting every individual teacher to engage with their own perceptions of the subject and how they can build their own capacity to resolve the rows they have to deal with in real terms. In order to advance the teacher training further, there is now an online training programme, blended learning training for teachers (mixing online with group workshops) and a two hour modules that can be delivered as evening classes or after school, as part of in-service training. The SALT Process is also taught as part of the Masters Programme in the Edward M Kennedy Institute of Mediation and Conflict Intervention and forms the basis of a new HETAC Level 7 Mediation Course due to be launched in The Institute of Technology Tallaght.This course in Tallaght will see the SALT Process developed further, this time for students and professionals from all backgrounds.

\section{In Conclusion}

Schools cannot do everything but the everyday rows and disputes that spring up take time and energy to sort out. It can be exhausting simply dealing with people! Looking at conflict as an opportunity to teach and thereby lessen its fall-out can only be a good thing. The existence of the SPHE gives a natural framework to teach the specific skills for the everyday peacemaker. As we can see from this article good self-awareness, communication skills and the ability to problem-solve are the bedrock of conflict resolution. World peace may be somewhat beyond our scope for the school term but creating little peacemakers who can sort out their own disputes is certainly possible. This, in turn, begins to change our communities. Imagine the difference a little sprinkle of Salt makes to a casserole or soup. Sprinkling the skills and ideas of peacemaking into the school can do the same. 


\section{References}

Bodine, R.J. and Crawford, D.K. (1998). The Handbook of Conflict Resolution Education. Jossey Bass. San Francisco.

Goleman, D (2004). Destructive Emotions and How we can overcome them. Bloomsbury.

Goleman, D Social Intelligence (2007) The Revolutionary New Science of Human Relationships. Bantam Books.

McAuslan F (2008) The S.A.L.T. Programme:Creative Solutions to Conflict. Learning Horizons, Dublin.

McAuslan, F and Nicholson, P (2010) The Resolving Book Series. Veritas, Dublin.

McAuslan, F and Nicholson, P (2012) Living with Separation and Divorce. BLackhall Publications, Dublin.

McAuslan, F and Nicholson, P. Edited by Lang M (2015) Divorce and Separation: A practical guide to making smart decisions. In publication.

Schwartz, J \& Begley, S (2002) The Mind and the Brain Neuroplasticity and the Power of Mental Force.

Fiona McAuslan is author of the SALT (Stop, Ask, Listen, Talk) Programme, an innovative programme, specially developed for the Irish and UK School Curriculum and is aligned to the key strands of the SPHE (Social, Personal, Health Education) Programme: Myself, Myself and Others, Relating to Others, Myself and the World. Through The S.A.L.T. Programme, children will learn what conflict is, what it feels like to be in conflict and how to negotiate effectively to create a better outcome for themselves and others. The programme focuses on building each child's capacity to develop and access their own skills set when dealing with difficult and sometimes emotional situations. 